\title{
Feed Forward Controller for Compensation of DC-Link Capacitor Unbalance Voltages and Ripple Reduction based BLDCM Drive System
}

\author{
Siddharth Jayashekar K, Joseph K D \\ Dept of EEE, Govt Rajiv Gandhi Institute of Technology, Kottayam \\ *Email: siddharthkrisun@gmail.com
}

\begin{abstract}
-
In this paper, a feed forward controller is used to compensate DC bus capacitor unbalance voltages at neutral point of two divide capacitors of half bridge boost converter \& control DC link voltage ripples of BLDCM drive system based half bridge boost AC-DC converter \& four switch inverter. Here input voltage is doubled as voltage doublers and is fed to four switch inverter to operate three phase BLDC motor. A four switch inverter uses a new switching pattern operating in six different modes instead of six switch inverter for the purpose of low cost effective applications. Simulation results indicate that a feed forward controller is used to compensate unbalance capacitor voltages at neutral point and control DC link voltage ripples, if three phase BLDC motor is coupled to two legs of four switch inverter while one phase of motor is connected to the neutral point of two divide DC bus capacitors of half bridge boost AC-DC converter. Improved power factor is achieved using half bridge boost AC-DC converter instead of diode rectifier.
\end{abstract}

Key words: Brushless DC (BLDC) motor, Half Bridge Boost AC-DC Converter, Four Switch Inverter, Feed Forward controller

\section{INTRODUCTION}

In this paper, permanent magnet motor with trapezoidal electromotive force is used and is driven by square wave currents. Brushless DC (BLDC) motor has stator with 3-phase concentrated winding which is displaced by $120^{\circ}$ with respect to each other, and it has rotor with permanent magnets. BLDC motor requires quasi-rectangle wave shape currents fed by voltage source inverter (VSI), in which energized stator winding leads the rotor magnet \& switches just as the rotor aligns with the stator in order to produce electromagnetic torque. Moreover, BLDC motor is easy for maintenance due to eliminations of mechanical commutators \& brushes which gives high power density, high reliability, high efficiency, high torque to volume ratio, less electrical noise \& simplicity in control. Nowadays BLDC motor has become popular in the field of applications such as computers, aerospace, military, automotive, industrial \& household products. However, In the BLDC motor drive, rotating magnetic motive force (MMF) is produced by current flowing through stator winding, Hall Effect sensors are used to detect changes in magnetic field \& to sense rotor position.

Here, we operate 3-phase BLDC motor by 4-switch inverter, which has similar function as 6-switch inverter in which conventional 6-switch inverter requires six power switching devices, three Hall Effect position sensors. For effective low cost minimization, a 4-switch inverter is used by eliminating drive components such as power switching devices, position sensors \& switching driver circuits. However, if we use 4-switch inverter to operate 3-phase BLDC motor, we have to consider unbalance capacitor voltage at neutral point. Because one phase of BLDC motor is connected to neutral point of two divide $D C$ bus capacitors of half bridge boost AC-DC converter. Due to unbalance capacitor voltages, there is occurrence of $D C$ link capacitors destruction, increase of DC link voltage ripples \& malfunction of drive components. In order to overcome the above problems, a feed-forward controller is used to compensate DC bus capacitor voltages \& controls $\mathrm{DC}$ link voltage ripples by sensing the voltage difference of two divide capacitors with respect to neutral points with feed forward gain and is given to the gates of power switches(S1\&S2) of half bridge boost converter.

Usually in this paper half-bridge boost AC-DC converter is used as voltage doublers in which controlled $\mathrm{DC}$ output voltage (310V) is higher than input $\mathrm{AC}$ voltage $(100 \mathrm{~V})$ operated in two modes of operation (a) mode- 1 : positive inductor-current slope mode (b) mode-2: negative inductor-current slope mode. Improved power factor is also achieved by using half-bridge boost converter. The 
paper is organized as follows mathematical model of BLDC motor, 4-switch inverter, half-bridge boost converter \& feed-forward controller. Modeling \& simulations are carried out in MAT/SIMULINK. Simulated results \& its analysis are shown in simulation studies section.

\section{EXPERIMENTAL}

\section{A. Modeling of BLDC Motor}

Fig. 1 shows equivalent circuit of BLDC motor, where $R, L_{a, b, c} \& L_{a b}, b c, c a$ are resistance, self inductance \& mutual inductance. $v_{a, b}, c, i_{a, b, c} \& e_{a, b, c}$ are voltage, current \& back-EMF of each phase. The modeling of BLDC motor is based on the following assumption to simplify the simulation as follows

1) The resistances of each phase are equal.

2) The self inductances of each phase are equal.

3) The mutual inductances of each phase are equal.

4) The iron and copper loss are neglected.

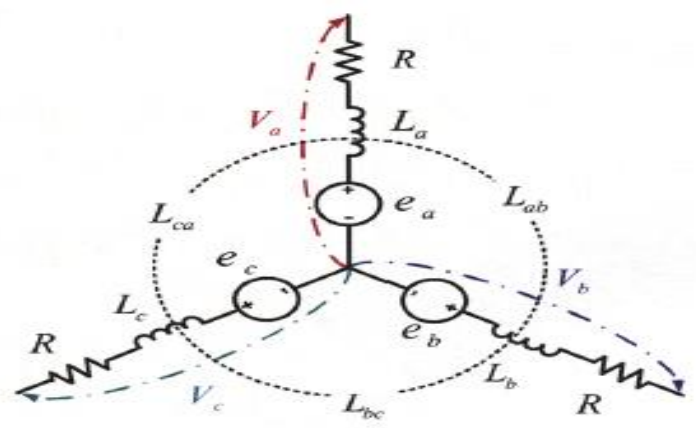

Fig. 1 shows Equivalent circuit of BLDC motor.

Then voltages of each phase are as following equations.

$$
\begin{aligned}
& v_{a}=R i_{a}+L \frac{d}{d t} i_{a}+e_{a} \\
& v_{b}=R i_{b}+L \frac{d}{d t} i_{b}+e_{b} \\
& v_{c}=R i_{c}+L \frac{d}{d t} i_{c}+e_{c}
\end{aligned}
$$

Electrical output of BLDC motor is defined by equation (2) the sum of multiplication of each back EMF by current of each phase of BLDC motor.

$$
\begin{aligned}
& P_{e}=e_{a} i_{a}+e_{b} i_{b}+e_{c} i_{c} \\
& P_{e}=T_{e} \omega_{r}
\end{aligned}
$$

According to the relation of above equation (2), (3), the electrical torque is as following equation.

$$
\begin{gathered}
T_{e}=\frac{e_{a} i_{a}+e_{b} i_{b}+e_{c} i_{c}}{\omega_{r}} \\
T_{e}=\frac{P}{2}\left(k_{a} i_{a}+k_{b} i_{b}+k_{c} i_{c}\right)
\end{gathered}
$$

The mechanical torque is given by equation (5).

$$
T_{m}=J_{m} \frac{d \omega_{r}}{d t}+B_{m} \omega_{r}+T_{L}
$$

B. Four Switch Inverter

In this paper, Four Switch Inverter is operated on six modes. The fig. 2 shows Inverter circuit for PMBLDCM drives system.

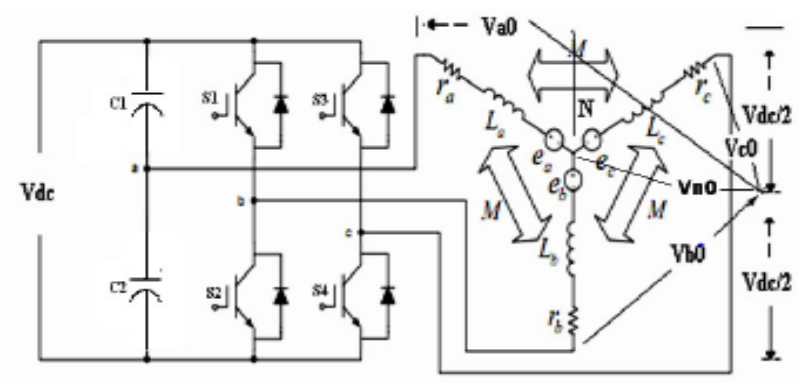

Fig.2 shows Inverter circuit for PMBLDCM Drive

Fig.3 shows Trapezoidal back-EMF, current waveforms and position Hall Effect sensor signals of a three-phase BLDC motor. To drive the motor with maximum and constant torque, the phase currents should be synchronized with the corresponding phase back-EMF voltages.

Moreover, at each mode only two phases are conducting and another phase is inactive.

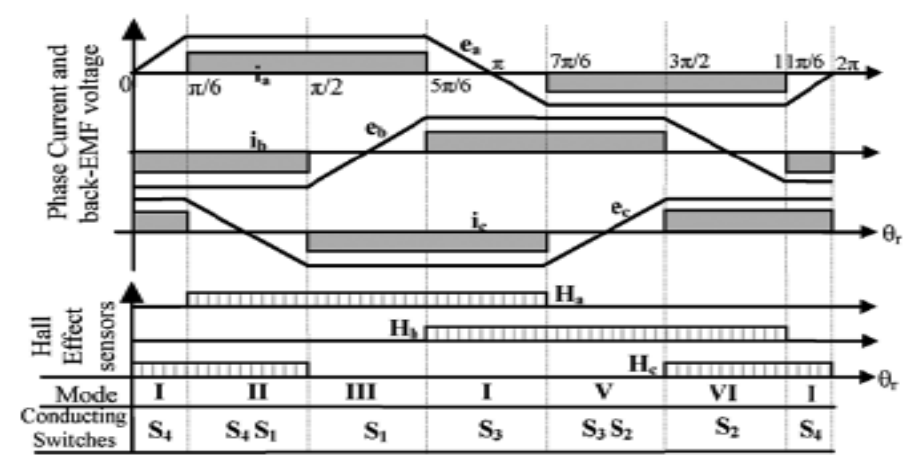

Fig. 3 shows phase back-EMF, current and position hall effect sensors waveforms of a 3 ph BLDC motor 
Switching pattern of four switch inverter in six modes is shown in Table 1. On two among six modes, Mode 2 \& Mode 5 inverter uses two complementary switching devices, while for other four modes, Mode 1, Mode 3, Mode 4, Mode 6, an inverter uses one switch \& neutral point of half bridge boost converter for completing the closed current path. These can be analyzed through the equivalent circuit of six modes of four switch inverter.

The four switch inverter uses new switching pattern, which is different from that of conventional six switch inverter for the purpose of low cost effective applications.

TABLE I

Switching pattern of Four Switch Inverter

\begin{tabular}{|c|c|c|c|}
\hline Operation Mode & Excited phase & Non-excited phase & Switching \\
\hline Mode 1 & C, B & A & T4 \\
\hline Mode 2 & A, B & C & T1, T4 \\
\hline Mode 3 & A, C & B & T1 \\
\hline Mode 4 & B, C & A & T2 \\
\hline Mode 5 & B, A & C & T2, T3 \\
\hline Mode 6 & C, A & B & T3 \\
\hline
\end{tabular}

C. Half bridge boost AC-DC converter \& feed forward controller

In the $A C$ mains, there has been a growing interest in the development of front-end rectifier topologies with input current wave shaping capability for unitary power factor. Among these, the half-bridge voltage-doubler boost converter provides an output voltage which will be at least twice the value of the peak of the input voltage for single-phase low-cost high power applications such as motor drives, because of its simple structure and high voltage $\mathrm{DC}$ bus.

Usually in this paper half-bridge boost AC-DC converter shown in fig. 9 is used as voltage doubler in which controlled DC output voltage (310V) is higher than input $A C$ voltage $(100 \mathrm{~V})$ operated in two modes of operation (a) mode-1: positive inductor-current slope mode (b) mode-2: negative inductor-current slope mode as shown in fig.10(a) \& 10(b). Improved power factor is also achieved by using half-bridge boost converter. Thus, the half-bridge boost AC-DC converter as a good option for the 110-V input voltage system. Since universal input voltage range $(85-270 \mathrm{~V})$ is often desirable in many applications

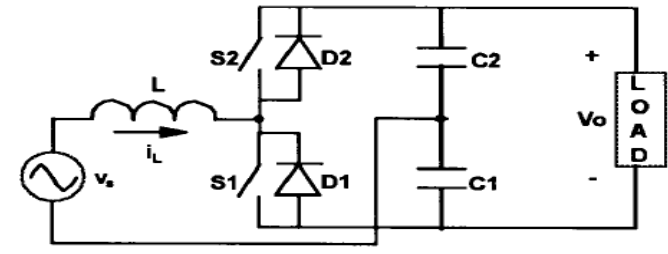

Fig.9 shows half bridge boost AC-DC converter circuit

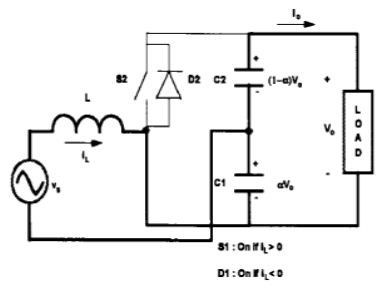

(a)

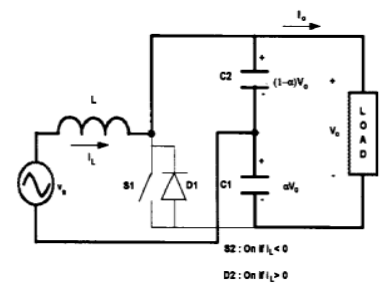

(b)
Fig. 10 shows two modes of operation of the half-bridge boost AC-DC converter circuit

The overall output voltage is the sum of the individual capacitor voltages and hence must be greater than twice the input voltage peak.

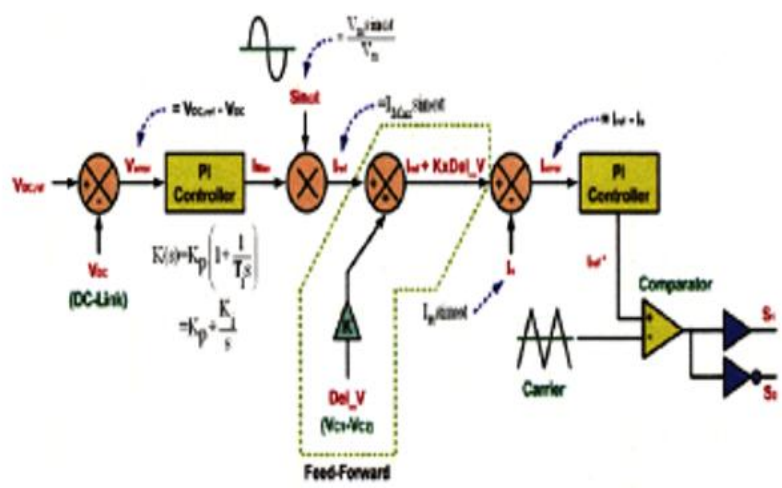

Fig.11 (a) shows Feed forward compensation control block diagram for DC link unbalance capacitor voltages

However, if we use 4-switch inverter to operate 3phase BLDC motor, we have to consider unbalance capacitor voltages $(\mathrm{Vc} 1 \& \mathrm{~V} c 2)$ at neutral point. Because one phase of BLDC motor is connected to neutral point of two divide DC bus capacitors of half-bridge boost AC-DC converter. Due to unbalance capacitor voltages, there is occurrence of DC-link capacitors destruction, increase of DC-link voltage ripples \& malfunction of drive components. Therefore, in this paper, a controller using feed forward compensation block diagram as shown in fig.11 (a) \& (b) is used to remove unbalance capacitor voltages \& control DC voltage ripples at the neutral point by sensing the voltages of two DC link divide capacitors of half bridge boost AC-DC converter. 
The feed forward strategy changes only the gain of the modulator according to the instantaneous ripple content of the dc-link. In this case the feed forward function uses arithmetical operators (multiplications or divisions). Hence they do not affect stability and frequency response of the original loop which is shown in fig.11 (b). Hence it reduces DC link voltage ripples \& has fast dynamic performance to large load variations without instability under reduced energy storage capacity in the DC link.

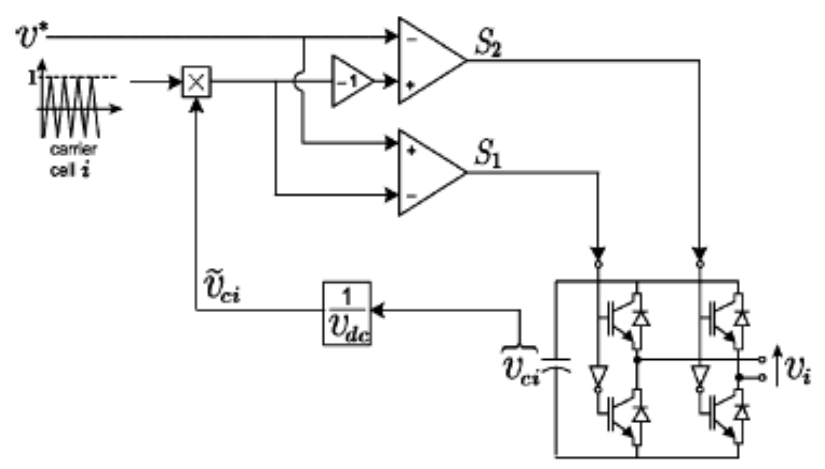

Fig.11 (b) shows Feed forward compensation control block diagram for DC link voltage ripples

\section{RESULTS AND DISCUSSIONS}

The overall system composed of 3 phases BLDC motor, half bridge boost AC-DC converter, four switch inverter, speed controller \& feed forward controller. Table 2 \& 3 shows parameters \& components values of 3 phases BLDC motor \& half bridge boost AC-DC converter for modeling \& simulating the system. MATLAB/SIMULINK software is used to simulate the system in this paper.

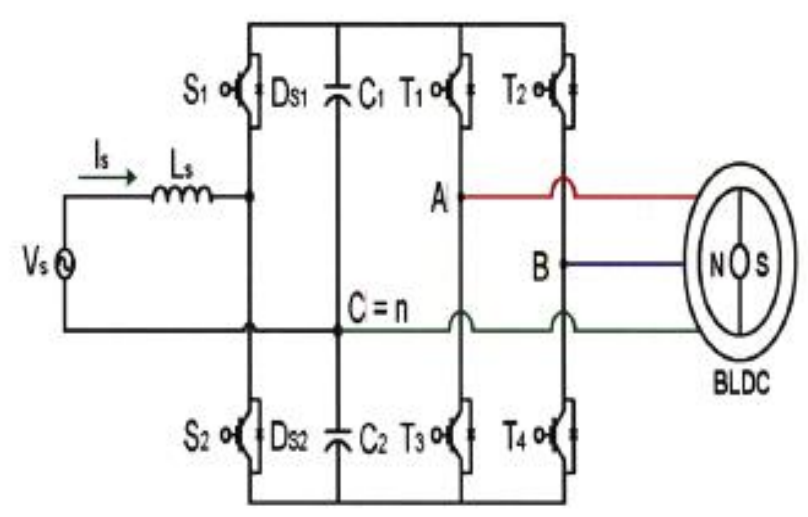

Fig.12 shows overall drive system for 3 phase BLDC motor
Table.2,Parameters of 3-ph BLDC motor

\begin{tabular}{l|ll}
\hline \multicolumn{3}{c}{$1.1 \mathrm{HP}, 310 \mathrm{~V}, 4$ pole, $50 \mathrm{~Hz}$} \\
\hline & 4600 & $(\mathrm{rpm})$ \\
Rated speed & 4.52 & $(\mathrm{~A})$ \\
Rated current & 2.2 & $(\mathrm{Nm})$ \\
Winding inductance & 3.285 & $(\mathrm{mH})$ \\
Winding resistance & 1.535 & $(\Omega)$ \\
Rotor inertia constant & $1.8 \mathrm{e}^{-4}$ & $\left.(\mathrm{Kg} \mathrm{m})^{2}\right)$ \\
Frictional co-efficient & 0.001 & $(\mathrm{Nm} / \mathrm{rad} / \mathrm{s})$ \\
Torque constant $\left(\mathrm{K}_{\mathrm{t}}\right)$ & 0.49 & $(\mathrm{Nm} / \mathrm{A})$ \\
Back EMF constant $\left(\mathrm{K}_{\mathrm{b}}\right)$ & 0.051 & $(\mathrm{~V} / \mathrm{rpm})$ \\
\hline
\end{tabular}

Table.3, Parameters \& components values of half bridge boost AC-DC converter

HALF BRIDGE BOOST AC-DC CONVERTER

\begin{tabular}{l|ll}
\hline & & \\
Input AC voltage $\left(\mathrm{V}_{\mathrm{s}}\right)$ & 100 & $(\mathrm{~V})$ \\
Output DC voltage $\left(\mathrm{V}_{\mathrm{o}}\right)$ & 310 & $(\mathrm{~V})$ \\
Line frequency & 50 & $(\mathrm{~Hz})$ \\
Inductor(L) & 1.27 & $(\mathrm{mH})$ \\
Capacitors $\left(\mathrm{C}_{1} \& \mathrm{C}_{2}\right)$ & 1000 & $(\mu \mathrm{F})$ \\
& & \\
\hline
\end{tabular}

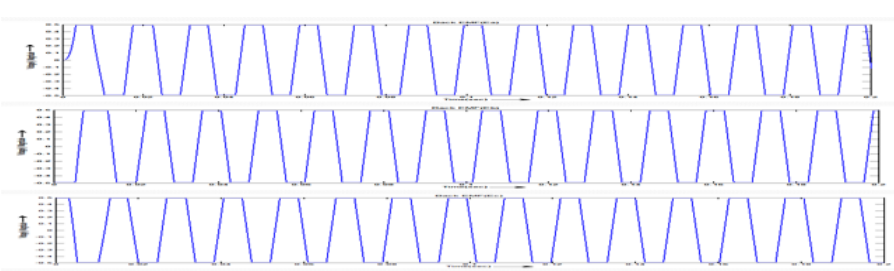

Fig.13 Trapezoidal back EMF of 3 ph BLDC motor

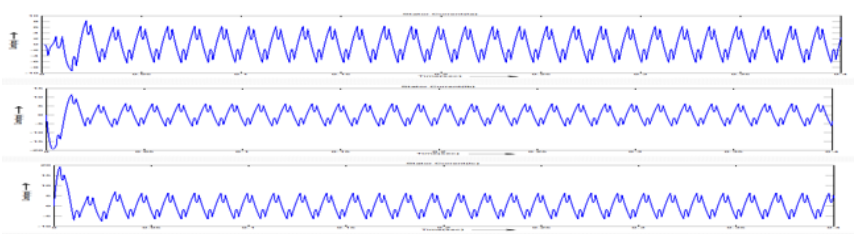

Fig.14 Stator phase current of 3 ph BLDC motor

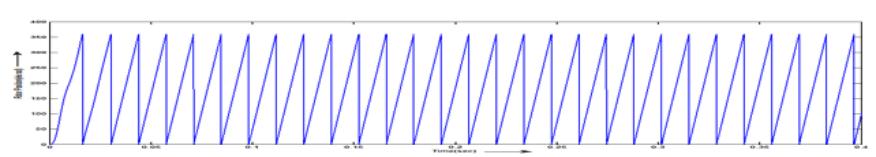

Fig.15 Rotor position

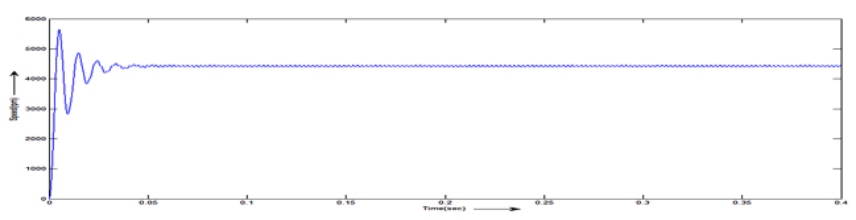

Fig.16 Rotor speed 


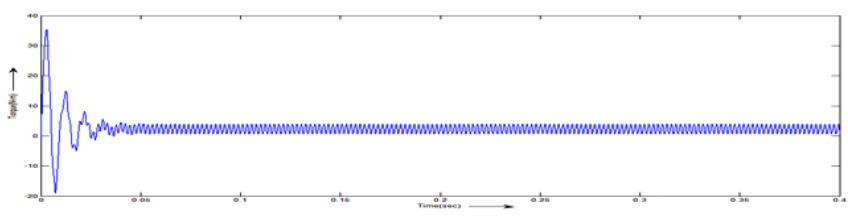

Fig.17 Torque

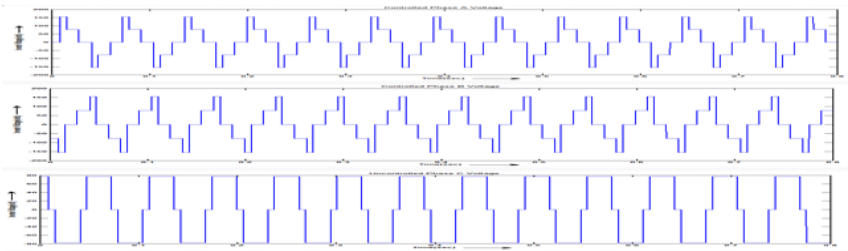

Fig.18 shows four switch inverter voltages for 3 ph BLDC motor

[a] Uncompensated DC link capacitor voltages \& DC link voltage ripple before feed forward controller of half bridge boost $\mathrm{AC}-\mathrm{DC}$ converter

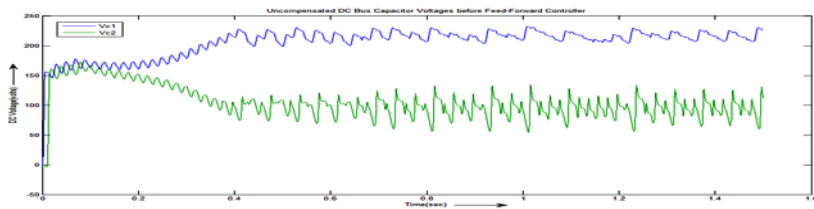

Fig.19 shows Uncompensated DC link capacitor $\left(\mathrm{V}_{\mathrm{C} 1}-\mathrm{V}_{\mathrm{C} 2}\right)$ voltages

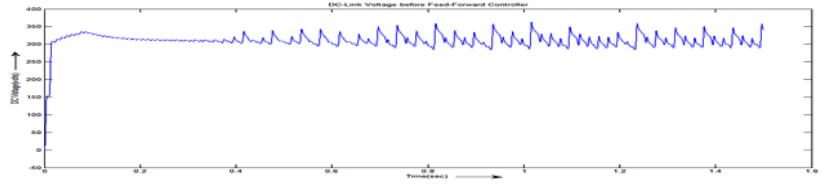

Fig.20 shows DC link voltage ripple

[b] Compensated DC link capacitor voltages \& DC link voltage ripple after feed forward controller of half bridge boost AC-DC converter

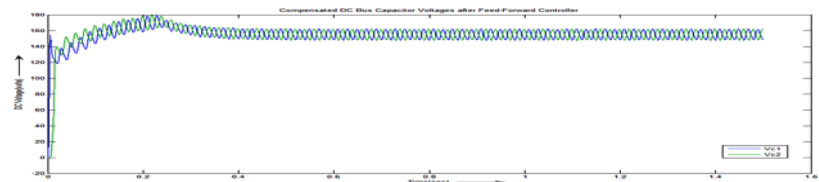

Fig.21 shows Compensated DC link capacitor voltages

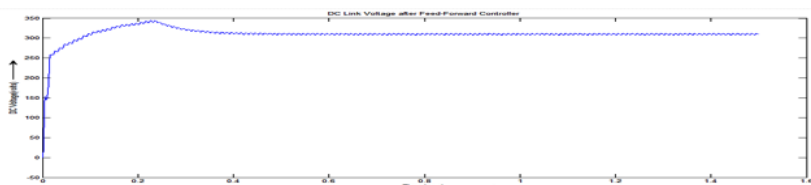

Fig.22 shows of DC link voltages ripple

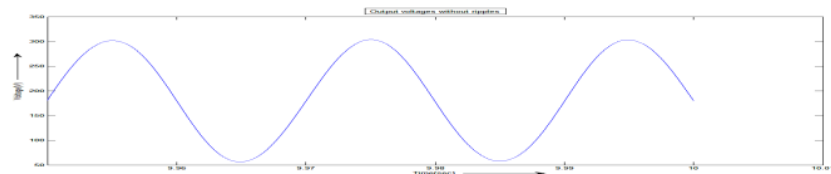

Fig.23 shows of Output voltages without ripples

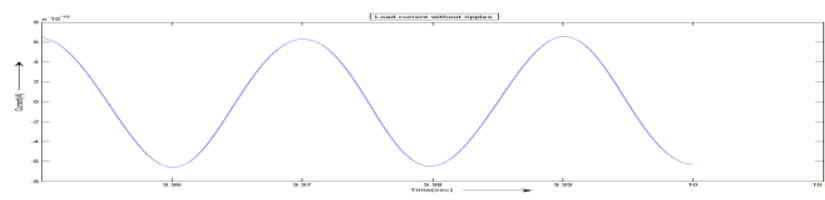

Fig.24 shows of Load current without ripples

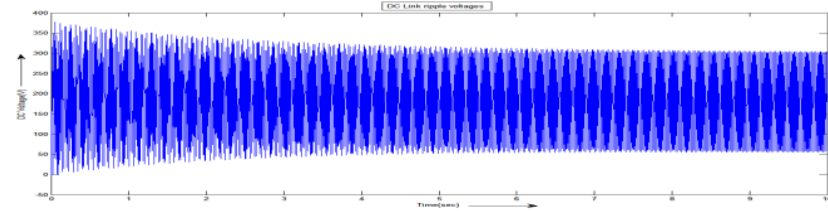

Fig. 25 shows of DC link voltages without ripples

Improved power factor near to unity is achieved by using half-bridge boost AC-DC converter instead of diode bridge rectifier.

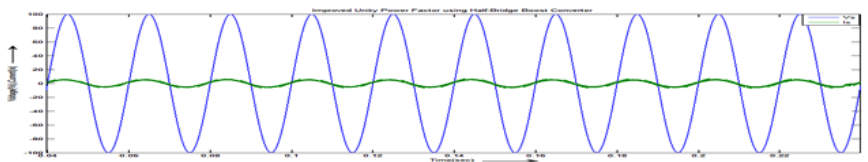

Fig. 26 shows of Improved power factor near to unity

\section{CONCLUSIONS}

In this paper, if three phase BLDC motor is coupled to two legs of four switch inverter while one phase of motor is connected to the neutral point of two divide DC bus capacitors of half bridge boost AC-DC converter. It generates the problem of unbalanced voltages \& voltage ripples at the neutral point of two divide capacitors of half bridge boost converter. Hence a feed forward controller is used to compensate DC bus capacitor unbalance voltages at neutral point of two divide capacitors of half bridge boost converter \& control DC link voltage ripples of BLDCM drive system based half bridge boost AC-DC converter \& four switch inverter. Here a four switch inverter uses a new switching pattern operating in six different modes instead of six switch inverter for the purpose of low cost effective applications. Therefore a half bridge boost converter is used as voltage doublers, and hence it also requires single phase $\mathrm{AC}$ power supply from input side.

Simulation results shows as the drive system of half bridge boost AC-DC converter becomes more unique \& robust by the use of feed forward control as it reduces DC link voltage ripples \& has fast dynamic performance to large load variations without instability under reduced energy storage capacity in the DC link. Hence this control method can be used in High power open loop powered 
systems without any errors for stability operations. Using half bridge boost AC-DC converter \& four switch inverter based BLDCM drive system can be widely used in low cost high power industrial drive applications and in domestic applications such as in vacuum cleaners, blowers \& fans. As a result improved power factor near to the unity is achieved using single phase half bridge boost AC-DC converter instead of three phase diode rectifier.

\section{ACKNOWLEDGEMENTS}

Behind every achievement lies an unfathomable sea of gratitude to the Almighty, without whom it would ever have come to existence. To him I lay the words of gratitude imprinted with me. With great pleasure I express my gratitude to My Parents, family and to all my friends without their support and encouragement this thesis would not have been possible.

Finally I express my sincere thanks to my thesis guide Asst. Prof. K.D. Joseph Dept of EEE, Govt RIT, Kottayam for the zeal with which he guided me in carrying out my thesis work. I am deeply indebted to him for his valuable guidance, constant encouragement and suggestions throughout the course of my thesis work.

\section{REFERENCES}

[1] Sang-Hoon Park, Young-Hwan Ryu, Won-cheol Lee, Jung-Hyo Lee, Jae-Sung Yu, Young-Ryul Kim, Chung-Yuen Won, "A fourswitch inverter and half-bridge boost converter based BLDCM drive system for the DC-link voltage unbalancing compensation", IEEE $7^{\text {th }}$ international conference on power electronics, Oct 22-26, 2007, pp.382-387.

[2] R.Krishnan, Electric Motor Drives: Modeling, Analysis, and Control, Prentice-Hall, Upper Saddle River, NJ, 2001.

[3] TJE Miller, Design of Brushless Permanent Magnet Motors, Clarendon Press. Oxford, 1994.

[4] Byoung-Kuk Lee, Tae-Hyung Kim, Mehrdad Ehsani, "On the Feasibility of Four-Switch Three-Phase BLDC Motor Drives for Low Cost Commercial Applications: Topology and Control", IEEE Trans. on Power Electronics, Vol. 18, No.1, January 2003.

[5] Four Switch Three Phase Inverter Control of BLDC Motor-2011 IEEE 1st International Conference on Electrical Energy Systems.

[6] F. A. Huliehel, F. C. Lee, B. H. Cho, "Small-signal modeling of single-phase Boost high power factor converter with constant frequency control", IEEE Power Electronics Specialists Conf. Rec., June 1992, pp. 475-482

[7] Ramesh Srinivasan, Ramesh Oruganti, "A Unity Power Factor Converter Using Half-Bridge Boost Topology", IEEE Trans. on Power Electronics, Vol. 13, No.3, May 1998.

[8] Samir Kouro, Pablo Lezana, Mauricio Angulo \& Jose Rodriguez, "Multicarrier PWM with DC-Link ripple feed forward compensation for multilevel inverters", IEEE Power Electronics, vol.23, no.1, January 2008, pp. 52-58. 